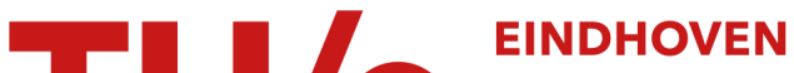 \\ UNIVERSITY OF \\ TECHNOLOGY
}

\section{Economic evaluation of leadtime reduction}

Citation for published version (APA):

Wouters, M. J. F. (1991). Economic evaluation of leadtime reduction. International Journal of Production Economics, 22, 111-120.

Document status and date:

Published: 01/01/1991

\section{Document Version:}

Publisher's PDF, also known as Version of Record (includes final page, issue and volume numbers)

\section{Please check the document version of this publication:}

- A submitted manuscript is the version of the article upon submission and before peer-review. There can be important differences between the submitted version and the official published version of record. People interested in the research are advised to contact the author for the final version of the publication, or visit the $\mathrm{DOI}$ to the publisher's website.

- The final author version and the galley proof are versions of the publication after peer review.

- The final published version features the final layout of the paper including the volume, issue and page numbers.

Link to publication

\section{General rights}

Copyright and moral rights for the publications made accessible in the public portal are retained by the authors and/or other copyright owners and it is a condition of accessing publications that users recognise and abide by the legal requirements associated with these rights.

- Users may download and print one copy of any publication from the public portal for the purpose of private study or research.

- You may not further distribute the material or use it for any profit-making activity or commercial gain

- You may freely distribute the URL identifying the publication in the public portal.

If the publication is distributed under the terms of Article 25fa of the Dutch Copyright Act, indicated by the "Taverne" license above, please follow below link for the End User Agreement:

www.tue.nl/taverne

Take down policy

If you believe that this document breaches copyright please contact us at:

openaccess@tue.nl

providing details and we will investigate your claim. 


\title{
Economic evaluation of leadtime reduction
}

\author{
Marc J.F. Wouters \\ Eindhoven University of Technology, Department of Industrial Engineering, P.O. Box 513, 5600 MB Eindhoven, \\ The Netherlands
}

(Received September 14, 1990; accepted in revised form June 5, 1991)

\begin{abstract}
Many companies have systematically worked on controlling and reducing leadtimes and have achieved impressive improvements. Further reduction of leadtime by such companies can only be achieved by relatively expensive projects. In this paper the economic evaluation of such projects is discussed.

Two important requirements for an economic evaluation of a project proposal for leadtime reduction are presented. The first requirement is to carefully analyse the consequences of leadtime reduction. A team that analyses the consequences should represent a variety of business functions, e.g. marketing, production, logistics and engineering.

The second requirement is to use the right kind of economic criterion. This criterion should be based on future cash flows caused by the leadtime reduction. It will be demonstrated that product costs are inappropriate to evaluate the economic consequences of leadtime reduction. This suggests that a decision about leadtime reduction should be made at the organisational level where managers are responsible for profits, not just for product costs.
\end{abstract}

\section{Introduction}

Leadtime is defined as the time a production department needs between accepting a production order and completing it. Leadtime is seen as an agreement between that production department and the logistics department of the company.

This paper discusses the question how much the leadtime of a production department should be reduced. An economic perspective is taken, i.e. leadtime should be reduced, if it improves the profitability of a company. Ways to reduce leadtime can be lowering work in progress, training and education, improving lay-out, reducing setup times, installing extra machine capacity, hiring extra man capacity, improving technological processes, changing product design, using more expensive materials, hiring professional consulting, etc. It is assumed that the least expensive actions to reduce leadtime are executed first. This means that additional actions to reduce leadtime become more expensive and could cost more than they yield. This poses the problem of how much a company should reduce leadtimes of their production departments. In this paper it is discussed how a project proposal for leadtime reduction can be economically evaluated.

In the literature it is discussed that investments in modern manufacturing systems must be economically justified (see for instance [1-3]). This also applies to expensive projects for leadtime reduction. For the economic evaluation of projects there are several well-known techniques, like discounted cash flow, net present value, internal rate of return, and payback time, which support decision making (see for instance $[4,5]$. These techniques are all based on future cash inflows and outflows which are caused by a project. In principle these techniques can also be applied to projects for leadtime reduction.

However, in practice companies often do not use these techniques, but instead use product costs to evaluate plans for leadtime reduction. As will be demonstrated, this is inappropriate and can give a wrong indication of the profitability of a project.

The techniques mentioned all assume that the 
relevant information is available. They are not concerned with retrieving information. See for instance Canada and Sullivan [3]. In the literature new evaluation techniques are discussed, but these assume that the information is available. See for instance Kivijärvi and Tuominen [6] and Moerman [7]. Literature that helps decision makers to get the relevant information does exist. For instance Miltenburg [8] describes how mathematical models can be used to analyse the consequences of flexible manufacturing systems. Azzone and Bertelé [9] describe how mix change decisions relate to timeliness and the economic consequences of this. Van der Veeken [10] discusses the economic effects of changing lotsizes. Corbey [11] analyses some consequences of investments in flexible capacity. In this paper it is discussed how the economic consequences of a plan for leadtime reduction can be analysed.

In Section 2 an example of an economic evaluation for such a plan is described. Some general economic consequences of leadtime reduction are examined in Section 3. This discussion can be helpful to make a more complete evaluation of a specific project proposal. In Section 4 the appropriateness of different economic criteria is discussed. Some organisational conditions to promote a complete and right kind of economic evaluation of leadtime reduction are presented in Section 5. Section 6 contains a summary and conclusions.

\section{Incomplete and wrong economic evaluation: $A$ simplified example}

In this section an example of an incomplete and wrong evaluation of a project proposal is presented. Although simplified, this example is not just a hypothetical case; in practice it is often done this way.

Fig. 1 represents the goods flow of a company. There are several inventories and two production departments (e.g. components manufacturing and assembly ). Per year 9.000 units are sold, 500 products do not meet quality standards and become scrap, and 500 products become unmarketable because they are in stock but demand changes. Total costs for scrap and unmarketable products are $\$ 180,000$ or $\$ 20$ per product. The selling price is $\$ 240$ per product.

Leadtime of department I is four weeks, leadtime of department II is two weeks. Suppose leadtime of department I could be reduced to two weeks by means of hiring extra direct labour and installing extra machine capacity. This requires an investment of $\$ 300,000$ and additional yearly costs of $\$ 55,000$. The investment will be depreciated in five years. The extra capacities are not used to produce more products, but to decrease waiting times of the products in the production department. Average product costs will rise by $\{\$ 300,000 / 5+\$ 55,000\} / 9.000=\$ 12.78$ per product. One could conclude that, from an economic point of view, the plan should not be implemented.

In this example two mistakes are made, which will be discussed in general in the next two sections. First, the evaluation is incomplete because important consequences outside department I are not taken into account. Second, the evaluation is wrong because product costs is not an appropriate economic criterion to evaluate the plan.

\section{Expensive proposals need complete analysis}

One mistake that is often made in the economic evaluation of project proposals for lead-

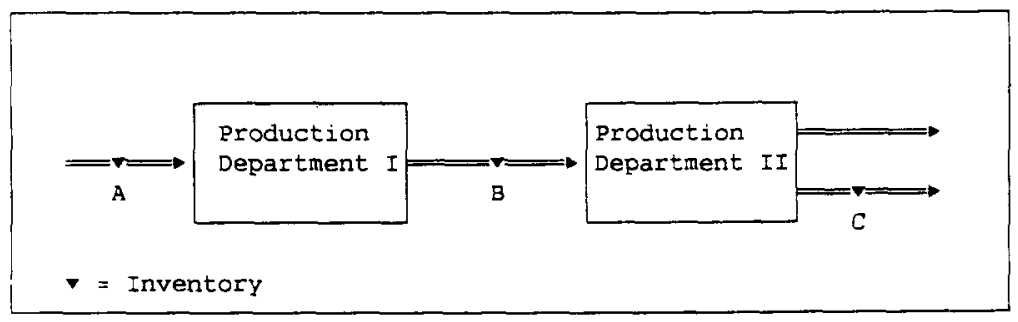

Fig. 1. Example of a goods flow. The leadtime of department I could be reduced. 
time reduction is that not all relevant consequences of the project are analysed. It is necessary to take into account consequences outside the department were leadtime is to be reduced.

In this section three categories of economic consequences of leadtime reduction are examined.

- Consequences of the manner in which leadtime reduction is realised.

- Consequences of improving the logistic performance to customers and their reactions to this improved logistic performance (external consequences).

- Consequences for inventory, scrap, quality etc. (internal consequences).

\subsection{How can leadtime reduction be realised?}

In this section some ways to realise leadtime reduction are presented. The applicability and costs of these depend on a specific situation.

In some situations [12] there is a relation between leadtime and utilisation of machines. When utilisation becomes higher, queues and waiting times become longer, which results in longer leadtimes. Therefore leadtime can be reduced by reducing machine utilisation. There are essentially two ways: increasing capacity or reducing production. Both ways have different economic consequences. Increasing capacity causes expenses. On the other hand, revenues decrease if machine utilisation is reduced by producing and selling less. In a situation where products (also) have to wait for labour, queues and waiting times can be reduced by reducing utilisation of labour.

A second way to reduce leadtime is to organise the work better and to improve the production control system. Examples are: using due-date based priority rules for separate tasks, monitoring the completion of orders, improving the availability of material, etc. These actions can cause expenses for extra overhead, for computer systems, for education and training, etc. However, some ways to reduce average leadtime can result in less reliable leadtime, for instance using priority rules based on shortest-processing-time [12]. Less reliable leadtimes can have negative economic consequences, which should be given attention.
A third way to reduce leadtime is to decrease the size of transport batches, thereby reducing the waiting time for transport. This may cause expenses for new transport systems.

A fourth way to reduce leadtime is to increase labour flexibility: operators being capable of more different tasks [12]. This may cause expenses for training of personnel and for higher wages.

Another way to reduce leadtime is to change lotsizes and to reduce setup time. The relation between lotsizes and queue times has been discussed by Karmarkar et al. [13]. Depending on the initial situation, increasing or decreasing lotsizes has a beneficial effect on leadtime. There are several economic effects of changing lotsizes, see for instance Van der Veeken [10]. To facilitate decreasing lotsizes setup time reduction is important.

In the example in Section 2 of this paper it is assumed that leadtime reduction of two weeks in department I can be realised by hiring extra labour and buying extra machines. This requires an initial investment of $\$ 300,000$ and additional yearly costs of $\$ 55,000$.

\subsection{What are the external consequences of leadtime reduction?}

External consequences are improvements of the performance towards customers and their reaction to this. Two possible performance improvements can be achieved by leadtime reduction,

- shorter delivery times

- shorter times to adapt products.

Before these effects can be discussed, an important concept must be explained: the Customer Order Decoupling Point.

\subsubsection{Customer order decoupling point (CODP)}

In this article the concept of the customer order decoupling point (CODP) is used, based on Van Hees $[14,15]$. The CODP marks a distinction in the way the production is driven. Production planning is directly based on real customer orders downstream from the CODP. Only those items are produced for which customer orders have been received and accepted. On the other 




Fig. 2. Five different positions for the customer order decoupling point. (Source: [15].)

hand, upstream from the CODP production planning is based on a forecast of future customer orders. To put it differently: after a customer order has been received, only those activities downstream from the CODP still have to be executed. The activities upstream from the CODP are already done, based on a forecast. A company must decide where in the goods flow it locates the CODP. In Fig. 2 five different CODP's are given.

The position of the CODP largely determines the delivery time to customers, because it determines how much needs to be done to complete an order. For example, there is a big difference regarding the delivery time between a situation where a product only has to be sent to a customer after an order has been placed, compared to a situation where a product must still be completely produced, assembled, tested, packed and sent after an order has been placed.

Different positions of the CODP have different risks. If products become more specific downstream, the more downstream the CODP is placed the greater is the risk that inventory becomes unmarketable. This risk depends on the structure of the bill of material and on the forecastability of customer demand. The more upstream the CODP is placed, the greater is the risk that delivery times cannot be realised and that calculated costs are exceeded. This is because completion times and costs are hard to predict due to technical uncertainty. Technical uncertainty is higher in an engineer-to-order situation than in a more repetitive situation (e.g. constructing houses ).

Because the position of the CODP involves risks and is important for the delivery time to customers, different positions of the CODP are possible for different products or for different customers. Furthermore, the position of the CODP must regularly be evaluated. 


\subsubsection{Leadtime reduction and delivery times}

Does leadtime reduction lead to a reduction of delivery time? To answer this question, one must distinguish between three different situations, as represented in Fig. 3.

(a) The CODP lies upstream from the department of which leadtime is to be reduced. There are two options.

(1) The position of the CODP remains the same. Leadtime reduction leads to a reduction of the delivery time to customers. This is situation a1 in Fig. 3.

(2) The position of the CODP is shifted upstream. The delivery time to customers remains the same, because the leadtime reduction is compensated by extra time needed to complete an ordere because of shifting the CODP. This is situation $\mathrm{a} 2$ in Fig. 3.

(b) The CODP lies downstream from the department of which leadtime is to be reduced. The delivery time to customers is not reduced. The time to replenish the CODP becomes shorter, therefore less safety stock in the CODP is needed. This is situation b in Fig. 3.

Now one can examine the external consequences of leadtime reduction in department $I$ in the example in this paper. Products with CODP A (in Fig. 1) have a delivery time to customers of six weeks. This is reduced to four weeks because of leadtime reduction in department I. One third of sales ( 3000 products per year) consists of these products. It would also have been possible to use (part of ) the leadtime reduction to shift the CODP further upstream and also purchase to order. The delivery time of products with CODP $B$ of $C$ cannot be reduced, but the safety stock for these products is reduced.

How do customers react to shorter delivery times? This question is only relevant in situation a1 and in situation a2, in so far as at least part of the leadtime reduction is indeed used to reduce delivery times to customers. How customers react depends on the standard with respect to delivery times on the selling market and on the performance compared to competitors. Possible effects are: higher selling prices, higher selling volume, earlier payments of customers. These effects must be quantified by the marketing function of the company. It has to be analysed what performance customers really care about and are prepared to pay for. See for instance Konijnendijk [16] and Christopher [17].

In the example of this paper it is assumed that



Fig. 3. It depends on the situation whether or not leadtime reduction can lead to shorter delivery times. 
customers are prepared to pay $3 \%$ higher prices for the reduction of leadtime from 6 to 4 weeks (products with CODP A).

\subsubsection{Leadtime reduction and adaptation of products}

Bertrand [18] argues that the quality of a product, in a broad sense, is ultimately tested in the market. If it turns out that a product does not satisfactorily fulfil the needs and tastes of customers or when those needs and tastes change, then the product design must be adapted and improved. The total time to adapt the product must be short when a company operates in a market where product innovation is important. Otherwise a company is always late when new market developments take place. This results in less sale and lower prices.

The time to adapt products consists of the time necessary to do market research, to change the product design, to get new materials, to produce and to distribute the product. So, leadtime reduction in a production department can help to shorten the total adaptation time of products. Whether leadtime reduction can cause a significant reduction of the total adaptation time of products depends on the other components of the adaptation time.

For a number of products, for instance consumer electronics, the life cycle of products is so short, that there is no time to adapt products. Still, fast adaptation remains important for designing new products. Experience is not used in the existing products, but in the design of new products. It is important to be at least as fast as competitors with the introduction of new products.

The adaptation and improvement of products could be called the "external quality". The "internal quality" consequences of leadtime reduction will be discussed in Section 3.3.2.

\subsection{What are the internal consequences of leadtime reduction?}

Internal consequences are consequences which primarily have an effect inside the company. Customers do not notice them. Consequences for inventory, for quality and for overhead will be examined.

\subsubsection{Consequences for inventory}

As seen in Section 3.1 and 3.2 leadtime reduction can lead to less work in progress and it can lead to less inventory between departments.

Now what are the relevant economic consequences of less inventory?

(a) Permanently less inventory can lead to less expenses for transport, handling, personnel, buildings, computer systems etc.

(b) Less inventory can lead to a reduction of unmarketable inventory. This can be used in two ways:

- produce as much as before, but sell more products instead of throwing them away; or

- sell as much as before, but produce less for that purpose.

(c) Less inventory releases tied-up cash which can be used for other investments.

(d) With less inventory changes of production level and production capacity can be smaller. This reduces the expenditures attached to these changes. This effect is described by Bertrand [18]. Figure 1 represents, as an example, the goods flow of a company. There are two departments and between the departments are inventories. The level of these inventories depends on the safety stocks and on the production series. In the departments are work in progress inventories. Suppose that the total inventory in the goods flow is at a level of 30 weeks demand, or 0.58 year. Bertrand calls this the relative pipeline inventory. Suppose that at some moment it turns out that the total demand is $\mathbf{5 \%}$ less than expected. So production level and inventories must be changed. The production level will be $5 \%$ less to adapt to the systematic lower demand. Moreover, there is a temporary extra change of the production level. The reason for this is that the relative pipeline inventory has increased, because the demand has decreased but the absolute total pipeline inventory has not changed. So an extra decrease of the production level is required to bring the relative pipeline level back to 0.58 year. This is represented in Fig. 4. If there is less inventory in the pipeline, the extra temporary production level change is smaller. This can save 


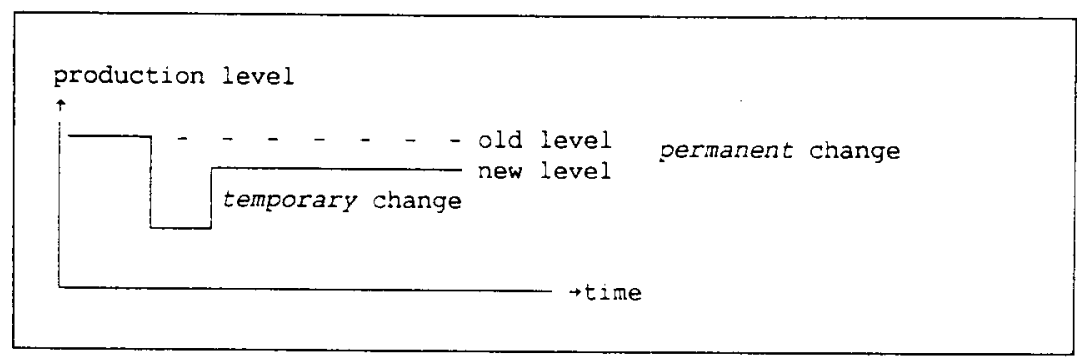

Fig. 4. Adaptation of production level when demand changes.

money, for instance for overtime rates.

In our example it is assumed that leadtime reduction will reduce unmarketable inventory from 500 products to 400 products per year. As a result of this 100 extra products are sold per year. It is assumed that demand is sufficient. Furthermore, in our example expenses for overtime rates will decrease by $\$ 10,000$ per year because fewer and smaller temporary production level changes are necessary. Expenses for interest will decrease by $\$ 5,000$ per year.

\subsubsection{Consequences for quality}

In Section 3.2.3 leadtime reduction in the context of time for adaptation of products was examined. It was referred to as external consequences for quality. Now the internal consequences of leadtime reduction regarding quality are discussed. See for instance Bertrand [18].

In the production process mistakes are made. Some mistakes can only be identified at quality inspections several processes further downstream. If certain mistakes return too often, processes have to be changed. It takes some time before the process can be changed: the bad products must reach the inspection point, they must be identified, the causes must be analysed and than some processes can be changed. New products are inspected to find out if the process is correct. If necessary the process is changed again. The longer the total time needed for all this, the greater the number of bad products that has been produced. The total time can be shortened by leadtime reduction. Therefore leadtime reduction can lead to less scrap and less expenses for repairing bad products.

A reduction of scrap can be used in two ways:
- sell more products (which used to be scrap) and/or

- produce less products for the same number of good products as before.

In the example introduced in Section 2 it is assumed that the leadtime reduction in department I will lead to less scrap in department II. This is because the results of a process in department I can only be measured in department II. Leadtime reduction makes it possible to adapt the process faster if the results are not satisfactory. Scrap in department II is reduced by 150 products per year. Because of this 150 extra products per year are sold.

We have regarded the consequences for quality as internal. But in a situation of insufficient quality control where bad products are actually sent to customers, quality improvements do have external consequences, because the quality performance to customer improves.

\subsubsection{Consequences for overhead}

Less inventory resulting by leadtime reduction often reduces overhead. Overhead expenses for inventory are caused by activities such as

- Changes of inventory must be registered.

- Actual inventory must be checked and compared with the registration.

- Errors in the registration must be analysed.

- Computer systems for inventory control must be built and maintained.

- Progress and due dates of work in progress must be controlled.

- Inventory that can deteriorate must be checked.

- Inventory that can become unmarketable must be checked.

Leadtime reduction saves money if it leads to 
less overhead activities if overhead capacity is flexible. Sometimes this saving is only possible if an activity can be avoided completely (for instance the costs of a computer system).

In the example it is assumed that expenses for overhead are reduced by $\$ 40,000$ per year.

\section{An economic evaluation should be based on future cash flows}

In Section 2 an example of an incomplete and wrong economic evaluation of a plan for leadtime reduction was presented. It was calculated that the average costs per product in department I would rise by $\$ 12.78$ because of the initial investment and additional yearly costs. One could conclude that, from an economic point of view, the plan for leadtime reduction in department I should not be implemented.

This economic evaluation was incomplete because important consequences of the leadtime reduction were not taken into account. In Section 3 some economic consequences of leadtime reduction were examined. The evaluation in the example in Section 2 was also wrong. The effect of leadtime reduction on the average product costs of a production department was used as an economic criterion. It is impossible to express economic consequences outside that particular department were leadtime is to be reduced in the average product costs of that department. For instance, leadtime reduction can lead to less scrap, to less inventory and to less unmarketable inventory in other production departments, elsewhere in the goodsflow. These kind of effects are not expressed in the average product costs of the production department where leadtime is to be reduced.

To include all product costs in the total goods flow, the total average product costs could be used as an economic criterion. For the example in this paper it would mean

- Total cost savings are: $\$ 40,000$ for overhead $+\$ 10,000$ for overtime rates $+\$ 5,000$ for interest $+25 \%$ of $\$ 180,000(=\$ 45,000)$ for scrap and unmarketable inventory = $\$ 100,000$ per year.

- Total extra costs per year are: $\$ 300,000 / 5+$ $\$ 55,000=\$ 115,000$ per year.
On balance costs rise by $\$ 15,000$ per year, or $\$ 1.67$ per product.

A major problem remains. Effects on revenues cannot be expressed in the total average product costs. For instance, leadtime reduction can lead to shorter delivery times and this can increase revenues through higher selling prices. This is not expressed in the total average product costs. Leadtime reduction can lead to less scrap and less unmarketable inventory. Instead of making bad or wrong products, the materials, machines, labour, etc. are used to make products that are sold. This increases profits.

We can conclude that average product costs (partial or total) cannot be used as an economic criterion for evaluation projects. In other words: projects that increase average product costs may well increase the profits of a company. Average product costs do no include all relevant consequences of a leadtime reduction.

An economic evaluation should be based on future cash flows. These include all future expenses for realising leadtime reduction and all revenues or savings resulting from leadtime reduction. There are several well-known techniques based on future cash flows, like discounted cash flow, net present value, internal rate of return and payback time.

For the example in this paper a complete and right economic evaluation of leadtime reduction in department I would have to include

- increased expenses because of the actions needed to realise the leadtime reduction: $\$ 300,000$ initially and $\$ 55,000$ yearly;

- increased future revenues because of higher selling prices, made possible by shorter delivery times: $3 \% \times \$ 240=\$ 7.20$; 3000 products $\times \$ 7.20=\$ 21,600$ per year.

- increased future revenues because of more products sold due to less scrap and unmarketable products and due to improve customer service: 250 products $\times \$ 240=\$ 60,000$

- decreased expenses for overhead, overtime rates and interest because of less inventory: $\$ 40,000+\$ 10,000+\$ 5,000=\$ 55,000$ per year.

Extra income per year is $\$ 81,600$, therefore the payback time of the initial investment is 3.7 years. 


\section{Organisational conditions}

The discussion on the consequences of leadtime reduction shows that the economic evaluation of a plan for leadtime reduction requires a variety of professional knowledge, regarding production, marketing, logistics, economics, engineering, development, etc. This suggests that the economic evaluation of a plan for leadtime reduction should be the responsibility of a team which includes these different fields.

Furthermore, decisions about leadtimes should be made at a level in the organisation where managers are responsible for profits and not just for product costs. This organisational condition has to do with the problem discussed before that product costs are often used an as an economic criterion to evaluate projects, although this criterion does not always reflect the true effects of a project on the profitability of the company. The use of product costs for this purpose may be caused by the way people are held responsible. If this responsibility concerns product costs and not profits, then it is likely that the evaluation of a project is based on product costs. From an economic point of view this is not optimal and therefore a manager who decides about leadtimes should be responsible for profits.

\section{Summary and conclusions}

In this paper the economic evaluation is discussed of project proposals for leadtime reduction of a production department. This is especially relevant for companies who have already implemented all inexpensive actions to reduce leadtime and who can only achieve additional leadtime reduction by expensive and complicated changes.

The focus was not on new theoretical concepts. Two important requirements for an economic evaluation of a plan for leadtime reduction were examined. Some organisational conditions that help to meet these requirements were also discussed.

The first requirement is that the evaluation should take into account the effects of leadtime reduction which occur outside the department where leadtime is reduced. Some possible eco- nomic consequences of leadtime reduction of a production department were presented. Some effects cause extra expenditures, others save money or increase revenues. So it depends on the characteristics of a specific project whether it contributes to the profitability of the company.

The first kind of consequences concern the manner in which leadtime reduction is realised. Leadtime reduction sometimes requires a reduced utilisation of machines. This can be achieved by less production and/or by extra capacity. These actions have important effects on expenditures and on revenues.

The second kind of consequences are external: how does the performance towards customers improve and how do customers react to such an improvement. Leadtime reduction can have two kinds of external consequences: shorter delivery time and faster adaptation of products. For the effect on delivery time the position of the customer order decoupling point is crucial. The effect on the speed of adaptation depends on the size of the leadtime reduction relative to the time needed for market research, product design, other steps in production, distribution etc. Whether shorter delivery times and faster product adaptation have effects on sales depends on the market and on the performance relative to competitors.

The third kind of consequences are internal. Leadtime reduction can lead to less inventory which has several positive economic effects. Furthermore, leadtime reduction can reduce scrap in production due to faster feedback on technical processes.

Analysis of these consequences requires a variety of professional knowledge. A team that is responsible for the evaluation of a plan for leadtime reduction should therefore include fields like production, marketing, logistics, engineering, etc.

The second requirement for an economic evaluation of a project is that it must be based on future cash flows caused by the project. In practice however product costs are often used as an economic criterion. This is inappropriate, because product costs cannot express all relevant economic consequences of leadtime reduction. Decisions about leadtimes should therefore be made at the organisational level where managers are 
responsible for profits, not just for product costs.

\section{References}

1 Kaplan, R.S., 1986. Must CIM be justified by faith alone? Harvard Business Rev., 64: 87-95.

2 Kaplan, R.S. and Atkinson, A.A., 1989. Advanced Management Accounting. Prentice-Hall, Englewood Cliffs, MA.

3 Canada, J.R. and Sullivan, W.G., 1990. Persistent pitfalls and applicable approaches for justification of advanced manufacturing systems. Eng. Costs Prod. Econ., 18: 247-253.

4 Horngren and Foster, 1987. Cost Accounting: A Managerial Emphasis. Prentice-Hall, Englewood Cliffs, MA.

5 Mills, R., 1988. Capital budgeting: The state of the art. Long range planning, 21 (4): 76-81.

6 Kivijärvi, H. and Tuominen, M., 1990. Logistics management: A method for evaluation of production-distribution investments. In: Proc. 6th Int. Working Seminar on Production Economics, Austria.

7 Moerman, P.A., 1988. Economic evaluation of investments in new production technologies. Eng. Costs Prod. Econ., 13: 241-262.

8 Miltenburg, G.J., 1987. Economic evaluation and analysis of flexible manufacturing systems. Eng. Costs Prod. Econ., 12: 79-92.

9 Azzone, G. and Bertelé, U., 1990. Idle capacity and timeliness in mix change decisions. Eng. Costs Prod. Econ., 18: 269-274.
10 Van der Veeken, H.J.M., 1988. Kosteninterpretatie bij logistieke beslissingen. Bedrijfskunde, 60(1): 20-30 (in Dutch).

11 Corbey, M., 1990. Measurable economic consequences of investments in flexible capacity. In: Proc. 6th Int. Working Seminar on Production Economics, Austria.

12 Bertrand, J.W.M. and Wortmann, J.C., 1981. Production Control and Information Systems for ComponentManufacturing Shops. Elsevier, Amsterdam.

13 Karmarkar, U.S., Kekre, S. and Kekre, S., 1985. Lotsizing in multi-item multi-machine job shops. IIE Trans., 17 (3): 290-297.

14 Van Hees, R.N., 1984. Organisatiestructuur en integrale besturing als basis voor voorraadbeheersing. Interne Philips Publicatie, vp45N, O\&E informatiecentrum (in dutch).

15 Van Hees, R.N., 1987. Organisatiestructuur en integrale besturing als basis voor voorraadbeheersing. In: W. Monhemius (ed.), Logistiek Management. Kluwer, Deventer (in dutch).

16 Konijnendijk, P.A., 1990. Setting customer service levels; An overall cost approach. In: Proc. 6th Int. Working Seminar of Production Economics, Austria.

17 Christopher, M., 1986. Reaching the customer: Strategies for marketing and customer service. J. Marketing Manage., 2 (1): 63-71.

18 Bertrand, J.W.M., 1988. Kostenverlaging door logistiek, B\&id, advance copy (in Dutch) 